\title{
A Study To Assess The Effectiveness Of Structured Teaching Programme On Prevention Of Myocardial Infarction Among Young Adults Residing At Selected Villages In Kirumambakkam Primary Health Centre, Puducherry.
}

*Dr. Prof.P.Genesta Mary Gysel, **Prof.Mrs. R. Uma \& **Mrs.K.Sivaranjiny

\begin{abstract}
:
Myocardial Infarction is a leading cause of death in industrial nations. Even in a developing country like India, it is emerging as a major public Health problem. World Health Organization predicts that CAD will become the major cause of death in almost all countries by 2020 This study was aimed to assess the effectiveness of Structured Teaching Programme on Prevention of Myocardial Infarction among Young Adults residing at selected villages in Kirumampakkam Primary Health Centre, Puducherry. The study was conducted in two villages Manapet and Moorthikuppam, 60 young adults were selected by using non probability convenience sampling technique and pre- experimental one group pre-test post-test research design was adopted for this study. The study result shows that the paired " $t$ "- test value of knowledge is ' $t$ ' $=25.05$ at $p<0.0001$, Hence it is very highly significant, The paired test " $t$ " value of attitude is $t^{\prime}=10.902$ at $p<0.001$ it is highly significant and the paired test " $t$ " value of practice is $t^{\prime}=6.051$ at $p<0.01$ it is significant. The pre test and post test mean difference for knowledge, attitude and practice was 6.80, 19.3, 2.3 respectively. Thus there is a significant difference between pre-test and post-test score of knowledge, attitude and practice. Hence there is significant improvement in posttest level of knowledge, attitude, and practice, hence it is highly effective.
\end{abstract}

Key words: Myocardial Infarction, STP, Knowledge, Attitude, Practice, Young Adults

\section{INTRODUCTION}

The WHO has drawn attention to the fact that Coronary Artery Disease modern epidemic of developing countries. Myocardial Infarction is a leading cause of death in industrial nations. Even in a developing country like India, it is emerging as a major public Health problem. Although CAD declined in developed countries from 1980 to 2000, the World Health Organization predicts that CAD will become the major cause of death in almost all countries by 2020, with over 10 million deaths per year. Progressive urbanization and adoption of a "western" lifestyle contributed to the rising burden of cardiovascular disease in the developing countries.(4)

American Heart Association (2013) quoted that risk factors and risk behaviors in keeping with the overall goal of preventing the onset and progression of CVD and maintaining optimal cardiovascular Health across the broader segment of the population and across the life span.(5)

\section{*Principal, **Vice Principal \& *** Lecturer Sabari College Of Nursing, Puducherry,}


Thus the investigator has planned to provide structured teaching programme on prevention of Myocardial Infarction in a view of creating awareness among Young adults and making them to Practice simple seven Healthy life style recommended by American Heart Association 2016 Such As Healthy Diet, Physical Activity, Maintaining Body Weight, Smoking Cessation, Control Of Blood Cholesterol, Blood Sugar, Blood Pressure.

\section{OBJECTIVES}

- To assess the pre-test level of knowledge, attitude and practice on prevention of myocardial infarction among young adults.

- To assess the post-test level of knowledge, attitude and practice on prevention of myocardial infarction among young adults.

- To evaluate the effectiveness of structured teaching programme on prevention of myocardial infarction among young adults.

- To determine the correlation between the pre-test and post-test level of knowledge, attitude and practice on prevention of myocardial infarction among young adults.

- To associate the pre-test level of knowledge, attitude and practice on prevention of myocardial infarction among young adults with their selected demographic variables.

\section{RESEARCH METHODOLOGY}

The study was conducted in two villages Manapet and Moorthikuppam , The target population of the study was 60 young adults who were at risk of developing myocardial infarctio. They were selected by using non probability convenience sampling technique and pre- experimental one group pre-test post-test research design was adopted for this study

\section{RESULTS AND DISCUSSION}

$\begin{array}{lllr} & \text { The frequency and } \\ \text { percentage } & \text { wise distribution of }\end{array}$ demographic variables of young adults shows that majority $29(48.3 \%)$ were in the age group of 31-35 years, this shows as the age increases the risk for developing myocardial infarction also increases.

Regarding Educational status majority $32(53.5 \%)$ young adults had at least high school level of education, even though they are at risk of developing myocardial infarction due to lack of awareness on prevention of myocardial infarction among young adults.

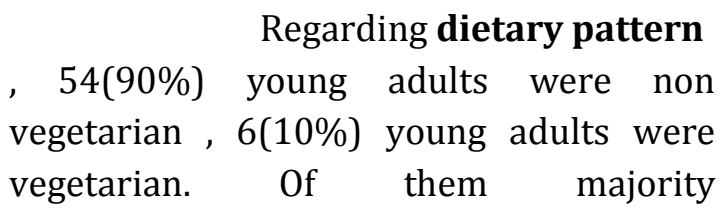
22(36.7\%)young adults were consuming more oily and spicy foods. This result shows that the risk of developing Myocardial Infarction is high among non vegetarians, and those who are specifically consuming more oily and spicy foods.

habits $33(55 \%)$ young adults were chewing betel leaves, $15(25 \%)$ of them were smokers , $7(11.7 \%)$ of them were alcoholics, $5(8.3 \%)$ of them were drug abusers .This result shows that tobacco usage can predispose to myocardial infarction

Regarding the nature of risk group majority of young adults 32(53.3\%) were having obesity, $10(16.7 \%)$ of them were having hypertension, 2(3.3\%) of them were having diabetes mellitus, , $13(21.7 \%)$ were having unhealthy habits. 
Comparison of pre-test and post-test level of knowledge, attitude and practice on prevention of myocardial infarction among young adults.

$\mathrm{N}=\mathbf{4 0}$

\begin{tabular}{|c|c|c|c|c|c|c|c|c|c|}
\hline \multirow{2}{*}{ Variables } & \multicolumn{3}{|c|}{ Pre-test } & \multicolumn{3}{|c|}{ Post test } & \multirow{2}{*}{$\begin{array}{c}\text { Mean } \\
\text { difference }\end{array}$} & \multirow[b]{2}{*}{ t-value } & \multirow{2}{*}{$p$-value } \\
\hline & Mean & Median & \begin{tabular}{|l|} 
Standard \\
deviation
\end{tabular} & Mean & Median & $\begin{array}{c}\text { Stand } \\
\text { ard }\end{array}$ & & & \\
\hline Knowledge & 11.37 & 12 & 2.804 & 18.17 & 18.5 & 4.477 & 6.80 & 25.05 & $\underset{* *}{<0.0001^{*}}$ \\
\hline Attitude & 25.35 & 25 & 4.554 & 44.65 & 45 & 1.624 & 19.3 & 10.902 & $<0.001^{* *}$ \\
\hline Practice & 3.45 & 3 & 1.016 & 5.75 & 6 & 1.257 & 2.3 & 6.051 & $<0.01^{*}$ \\
\hline
\end{tabular}

By Comparing the pre test and post test level of knowledge, attitude, and practice on prevention of Myocardial Infarction among young adults. The findings reveals that the paired test " $\mathrm{t}$ " value of knowledge is, $\mathrm{t}^{\prime \prime}=25.05$ and the $\mathrm{p}<0.0001$, Hence it is very highly significant, The paired test " $t$ " value of attitude is $t$ " $=10.902$ and the $\mathrm{p}<0.001$ it is highly significant and the paired test " $\mathrm{t}$ " value of practice is $t^{\prime \prime}=6.051$ and the $p<0.01$ it is significant.
The pre test and post test mean difference for knowledge, attitude and practice was 6.80, 19.3, 2.3 respectively. Thus there is a significant difference between pre test and post test score of knowledge, attitude and practice. Hence the structured teaching programme was highly effective.

* significant at the level of $\mathrm{p}<0.01$;

$* *$ significant at the level of $\mathrm{p}<0.001$ $* * *$ significant at the level of $\mathrm{p}<0.0001$

\begin{tabular}{|c|c|c|c|}
\hline \multicolumn{2}{|c|}{ Variable } & r-value & $p$-value \\
\hline $\begin{array}{c}\text { Attitude } \\
\text { Vs } \\
\text { Practice }\end{array}$ & Post-test & $0.448^{* *}$ & $<0.001$ \\
\cline { 2 - 4 } & Pre-test & -0.223 & 0.087 \\
\hline
\end{tabular}

Correlation between pre-test and post-test level of attitude with practice on prevention of myocardial infarction among young adults.

Correlation coefficient between the pre-test level of attitude and practice which is at $0.448^{* *}$, hence there is a positive correlation between attitude and practice.
As the young adults are not having positive attitude towards prevention of myocardial infarction hence they are not modifying the risk factors in their lifestyle practices is proved to have positive correlation between attitude and practice.

** Correlation is signified at the 0.01level (2-tailed) 
In association among 20 demographic variables such as age, nature of risk , dietary pattern, unhealthy habits, body mass index are statistically associated with level of knowledge, only age is statistically associated with level of attitude and there is a significant association between level of practice and age , type of work, nature of risk group, body mass index.

\section{RECOMMENDATIONS}

- Similar type of study can be conducted among high risk patient in hospital setting.

- Similar study can be conducted among adolescent in a view of promoting primordial prevention for the occurrence myocardial infarction.

- Similar study can be conducted among students of non medical colleges.

- Detailed knowledge regarding the dietary control, and aerobic exercise in high risk clients and sedentary workers could be studied

\section{CONCLUSION:}

The main aim of the present study was to assess the effectiveness of Structured Teaching Programme on Prevention of Myocardial Infarction among Young Adults residing in selected villages at Kirumampakkam Primary Health Centre, Puducherry. Comparing the pre test\& post test scores, structured teaching programme on prevention of myocardial infarction provided by the investigator proved to be highly effective in the improvement of knowledge , attitude and practice among young adults.
If health teaching is implemented to all the high risk young adults, for better health status and for the prevention of myocardial infarction. Every individual can be protected from the occurrence of infarction.

\section{REFERENCE}

\section{Book Reference}

1. Basavanthappa BT. (2006). Text Book of Medical and surgical nursing.1st edition. New Delhi: Jaypee Brothers Medical Publishers (P) Ltd

2. Basavanthappa BT. (2007).Nursing Theories. 1st edition. New Delhi: Jaypee Brothers;

3. Black M J. (2004). Hawks. MedicalSurgical Nursing: clinical management for positive outcomes. 7thed. New Delhi: Elseiver

4. Brunner \& Suddaths. (2004). Text book of Medical Surgical Nursing.10th edition Philadelphia. Lippincott Company. 5. B.Srilakshmi (2005) Dietetics 5th edition. New Delhi. Published by New Age international private LTD.

\section{JOURNAL REFERENCE}

- Anne Underwood. 9 Super foods for your heart, Prevention January 2012.

- Benjamin Riggs, A good Heart is Indestructible, Elephant journal.(2011) December 7

- George krucik.28 healthy heart tips, health line.2013,march 28

- Gullar E. et al, Mercury, Fish, Oils, And The Risk of Myocardial Infarction. , The New England Journal of Medicine (2002).November 28

- KristianThygesen. et al. Myocardial infarction redefined. European Heart Journal(2000), 21(18).

- LeigoIalino et al. Myocardial infarction with normal coronary arteries, Journal of medical case report (2009), Volume $3: 24$. 